Ekonomica Sharia Volume 5 Nomor 2 Edisi Februari 2020 | 1

\title{
PENGENDALIAN HARGA PADA PROGRAM TOKO TANI INDONESIA CENTER PROVINSI SUMSEL DALAM PERSPEKTIF EKONOMI ISLAM
}

\author{
Amrillah \\ Mahasiswa Program Magister Fakultas Ekonomi dan Bisnis Islam \\ Univeristas Negeri Raden Fatah \\ Email: amrillah_UIN@radenfatah.ac.id
}

\begin{abstract}
Rice, Market, Price and government intervention are a unified whole that cannot be separated. If the market is not stable it will affect the price. This paper aims to describe and explain why controlling rice prices needs to be done by the government through the TTIC program in South Sumatra from the perspective of an Islamic economic perspective. study of the perspective of Islamic economics that recognizes free markets. Prices are submitted to the market where prices are formed at the request and supply so that a normal price is formed. The government is not allowed to intervene when prices are normal. The government is only justified in an emergency by promoting the concept of justice. The al-Hisbah institution functions as an independent institution that is free from the interests of certain groups. The intervention of the price of rice by the government aims to benefit the masses so that it does not overburden the community when the price of rice surges. This government program is carried out to keep prices stable when market demand increases. This type of research is field research conducted using a qualitative approach, this study departs from the conditions in the field in order to see and understand the phenomena that exist and are reversed in more depth. Symptoms include the views, thoughts, attitudes and actions of the informants, and also include the situations and conditions observed as well as the data which are the Sumatran TTI Center documents. The results of this study indicate that the government has carried out its role as a state institution that functions to control prices when prices rise in the community.
\end{abstract}

Keywords: Rice, Al-Misbah and Market Mechanisms

\section{DASAR PEMIKIRAN}

Harga komoditas beras yang selalu berfluktuasi dapat merugikan petani sebagai produsen, pengolah beras, pedagang hingga konsumen dan berpotensi menimbulkan keresahan sosial. Fluktuasi pasokan dan harga beras yang tidak menentu, tidak hanya akan menimbulkan keresahan sosial, tetapi juga akan mempengaruhi pengendalian inflasi (Pedoman Teknis Pengembangan Usaha Pangan Masyarakat Melalui Toko Tani Indonesia, 2017: 1).

Kenaikan harga beras digolongkan sebagai komponen inflasi bergejolak (volatilefoods), karena sifatnya yang mudah dipengaruhi oleh masa panen, gangguan alam, harga komoditas bahan pangan domestik dan internasional. Oleh karena itu, 


\section{2 | Amrillah Pengendalian Harga Pada Program Tani Indonesia Center Provinsi Sumsel.....}

hampir semua negara melakukan intervensi kebijakan untuk menjaga stabilitas harga beras pokok dan strategis (Sadono, 2013: 37).

Kebutuhan barang-barang pokok di Indonesia saat ini sedang mengalami krisis, dikarenakan harga barang-barang pokok yang melonjak naik. Sehingga masyarakat kesulitan memenuhi kebutuhannya sehari-hari. Ini merupakan hal yang harus diatasi dan dicari jalan keluarnya. Apabila bahan-bahan dasar seperti beras, sagu, minyak tanah, minyak goreng dan lain-lain akan habis suatu saat nanti, itu akan berakibat buruk pada anak cucu kita (Sadono, 2013: 4).

Dalam tulisan ini, penulis menggunakan wacana naik turunnya harga beras di Sumatera Selatan serta kebijakan apa yang dilakukan oleh pemerintah. Penulis akan menghubungkannya dengan mekanisme pasar Islam. Sistem pasar dalam Islam adalah pasar bebas. Harga didasarkan pada kekuatan permintaan dan penawaran. Pemerintah tidak dibenarkan melakukan intervensi harga. Kecuali dalam keadaan darurat.

\section{METODE PENELITIAN}

Jenis penelitian ini adalah penelitian lapangan (field research) yang dilakukan dengan menggunakan pendekatan kualitatif. Menurut Anselm Strauss dan Juliet Corbin, penelitian kualitatif adalah jenis penelitian yang temuan - temuannya tidak diperoleh melalui prosedur statistik atau bentuk hitungan lainnya (Strauss dan Corbin, 2007: 4).

Penelitian ini bertolak pada keadaan yang ada di lapangan guna melihat dan memahami gejala-gejala yang ada maupun dibalik yang ada tersebut secara lebih mendalam. Gejala-gejala, meliputi pandangan, pikiran, sikap dan tindakan para informan, dan juga meliputi situasi dan kondisi yang diobservasi maupun data yang merupakan dokumen TTI Center Sumsel. Gejala-gejala tersebut merupakan satu kesatuan yang utuh, satu sama lain saling terkait dan saling mempengaruhi, sehingga data yang diteliti bersifat saling mendukung, setelah data tersebut terkumpul, peneliti menggambarkannya dalam bentuk uraian/kata-kata yang disusun menurut sistematika penelitian ilmiah. Sumber data dalam penelitian ini terdiri dari sumber data primer dan data sekunder. Sumber data primer adalah data yang diperoleh peneliti dari sumber asli (Muhammad, 2013: 103). 
Ekonomica Sharia Volume 5 Nomor 2 Edisi Februari $2020 \mid 3$

Data Primer dalam penelitian ini adalah data pokok yang diambil dari Dinas Pertanian Provinsi Sumsel khusus yang membidangi atau mengelola toko Tani Indonesia Center Provinsi Sumatera Selatan dan para pelaksana, serta hasil wawancara dengan masyarakat selaku konsumen dan anggota Gapoktani. Data Skunder dalam penelitian ini adalah data yang diambil dari Lokasih penelitian dan buku yang petunjuk teknis serta Internet berupa dokumentasi, yaitu dokumen-dokumen atau arsip-arsip yang berhubungan Dengan Kegiatan Produksi Dan Dsitribusi Serta Rantai Harga Beras yang didapat di Toko tani center sumatera selatan.

Maka tehnik pengumpulan data yang dipakai dalam penelitian ini adalah observasi, wawancara, dan dokumentasi. Data yang telah dikumpulkan, dianalisa secara deskriptif kualitatif yaitu analisa yang memberikan gambaran dari data yang diperoleh dan menghubungkannya satu sama lain untuk mendapatkan suatu kesimpulan, yaitu proses menyusun data agar dapat ditafsirkan.

\section{PEMBAHASAN}

\section{Konsep Dasar Ekonomi Islam}

Prinsip dasar ekonomi Islam adalah keyakinan kepada Allah SWT sebagai Rabb dari alam semesta. Ikrar akan keyakinan ini menjadi pembuka kitab suci umat Islam, dalam ayat :"Dan dia Telah menundukkan untukmu apa yang di langit dan apa yang di bumi semuanya, (sebagai rahmat) daripada-Nya. Sesungguhnya pada yang demikian itu benar-benar terdapat tanda-tanda (kekuasaan Allah) bagi kaum yang berfikir." (AlJaatsiyah: 13)

Allah telah menetapkan bahwa manusia berperan sebagai khalifah, bumi adalah lapangan dan medan, sedang manusia adalah pengelola segala apa yang terhampar di muka bumi untuk di maksimalkan fungsi dan kegunaannya. Tanggung jawab manusia sebagai khalifah adalah pengelola resources yang telah disediakan oleh Allah secara efisien dan optimal agar kesejahteraan dan keadilan ditegakkan.

Harga merupakan salah satu faktor utama, meskipun bukan faktor satu-satunya yang mempengaruhi pilihan pembeli. Harga menjadi faktor utama pilihan pembeli semakin terlihat di antara kelompok-kelompok miskin. Namun, harga bukan menjadi faktor utama pilihan pembeli bagi masyarakat yang mampu/kaya. Namun, teori ini 
4 | Amrillah Pengendalian Harga Pada Program Tani Indonesia Center Provinsi Sumsel.....

hanya berlaku bagi produk-produk di luar kebutuhan bahan pangan. Untuk kebutuhan bahan pangan yang termasuk kebutuhan primer, akan memiliki dampak garis lurus dengan turunnya pembelian pada kebutuhan sekunder dan pertumbuhan ekonomi (Riza, 2010: 47).

Singkat kata kita bisa lihat dari situasi pasar dan kondisi pasar yang begini beberapa gambaran. Pertama, Jika harga barang primer meningkat, sementara pendapatan tetap, akan menyebabkan harga barang sekunder pun akan meningkat. Kedua, Pembelian terhadap barang sekunder pun akan menurun. Ketiga, Perubahan harga barang konsumsi menyebabkan tingkat substitusi (pergantian) terhadap barang konsumsi akan berubah pula.Dengan demikian, dari penjelasan di atas, maka harga kebutuhan primer harus dikendalikan oleh pemerintah. Jika tidak, maka akan terjadi kelesuan ekonomi negara, yang berimbas pada penurunan daya saing produk lokal dan penurunan pertumbuhan ekonomi(Riza, 2010: 47).

Untuk mengatasi kondisi kekurangan pangan dapat dilakukan dengan peningkatan produksi pertanian/peternakan, serta pemanfaatan sumber daya lokal untuk dikonsumsi (Airlangga, 2008: 76). Pada praktinya dilapangan Kementerian Pertanian Republik Indonesia mengeluarkan kebijakan melalui peraturan menteri no. 06/KPTS/RC.110/J/2017 pada tanggal 23 januari 2017 tentang pedoman teknis pengembangan usaha pangan masyarakat melalui toko tani indonesia tahun 2017, dalam peraturan tersebut dijelaskan tentang juknis dilapangan pengembangan toko tani bagi para petani (Pedoman Teknis Pengembangan Usaha Pangan Masyarakat Melalui Toko Tani Indonesia, 2017: 4).

Toko Tani Indonesia (TTI) melakukan perubahan struktur pasar baru, dengan tetap menjaga keseimbangan antara produsen, pedagang, dan konsumen.Pada sistem awal, sebuah produk pangan harus melewati 8 step untuk menuju konsumen. Mulai dari petani $\rightarrow$ penggilingan (importir) $\rightarrow$ distributor $\rightarrow$ sub distributor $\rightarrow$ agen $\rightarrow$ sub agen $\rightarrow$ pedagang grosir $\rightarrow$ pedagang eceran $\rightarrow$ konsumen akhir. Panjangnya rantai pasok pangan dinilai sebagai salah satu hal yang menyebabkan harga pangan menjadi mahal (Pedoman Teknis Pengembangan Usaha Pangan Masyarakat Melalui Toko Tani Indonesia, 2017: 6). 
Ekonomica Sharia Volume 5 Nomor 2 Edisi Februari $2020 \mid 5$

Struktur baru yang ditawarkan oleh kementerian pertanian adalah membuat petani menyalurkan produk ke Gapoktan $\rightarrow$ Toko Tani Indonesia (TTI) dan langsung konsumen akhir. Diharapkan dengan sistem ini harga pangan menjadi murah dan produsen dapat tetap memperoleh keuntungan yang wajar. Kementerian Pertanian menggandeng pedagang untuk berpartisipasi mengoperasikan TTI (Pedoman Teknis Pengembangan Usaha Pangan Masyarakat Melalui Toko Tani Indonesia, 2017: 7).

\section{Lembaga Al-Hisbah}

Didalam Negara Islam terdapat perbedaan dasar yang timbul dari kenyataan, bahwasanya pengawasan atau peraturan datang dari "dalam" masyarakat sendiri, masyarakat yang sudah di pengaruhi oleh nilai-nilai Islam. Sedangkan di Negara kapitalis dan sosialis, peraturaan dipaksakan kepada masyarakat, dan masyarakat mau tidak mau harus menerima dan menaatinya (Mannan, 1997: 149-150).

Dalam konsep Ekonomi Islam cara pengendalian harga ditentukan oleh penyebabnya. Bila penyebabnya adalah permintaan dan penawaran, maka mekanisme pengendalian dilakukan melalui Intervensi Pasar. Sedangkan bila penyebabnya adalah distorsi terhadap permintaan dan penawaran, maka mekanisme pengendalian dilakukan melalui penghilang distorsi termasuk penentuan harga untuk mengendalikan harga pada keadaan sebelum distorsi (Mannan, 1997: 152).

Secara etimologi kata hisbah, berasal dari akar kata bahasa arab yang berarti "menghitung" dan 'membilang". kata hisbah juga sering digunakan bersamaan dengan kata "wilayah" yang berarti "permintaan", 'kekuasaan" dan 'kewenangan". Sehinggah susunannya menjadi "'wilayat al hisbah '. Secara istilah, hisbah adalah memerintahkan kebaikan apabila ada yang meninggalkanya, dan melarang kemungkaran apabila ada yang melakukannya (Zamakhasyari, 2003: 587)

Dalam mendefinisikan wilayah hisbah, ada beberapa pendapat. Menurut ibnu taimiyyah, yang dimaksud menyuruh dengan wilayah hisbah adalah muhtasib yang kewenangannya adalah menyuruh berbuat baik dan melarang. Dan menurut al-mawardi sehinggah menjadi kebiasaan dan melarang hal yang buruk ketika itu telah mejadi kebiasaan umum (UP3EI, 2009: 342) 
6 | Amrillah Pengendalian Harga Pada Program Tani Indonesia Center Provinsi Sumsel.....

Tujuan hisbah untuk menjamin bahwa semua pelaku ekonomi dapat memenuhi tugasnya antara satu sama lain dan mematuhi ketentuan syariat. Setiap tindakan kehatihatian perlu diambil untuk menjamin bahwa tidak ada pemaksaan, penipuan, pemafaaatan, pengabaian pasokan dengan tujuan menaikan harga.dan negara tidak perlu ragu-ragu untuk melakukan intervensi menakal pembatasan keadilan dan kejujuran telah dilanggar (Chapra, 2001: 64)

Tradisi hisbah diletakan langsung pondasinya oleh Rasulullah Saw, beliaulah Muhtasib (pejabat yang bertugas melaksanakan hisbah) pertama dalam Islam. Akan tetapi tugas pengawasan terhadap perekonomian masih dijalankan langsung oleh Nabi. pada saatitu sudah telihat bahwa Nabi memerintahkan seseorang untuk mengawasi dan menghakimi (menjadi qadhi) dalam sebuah daerah tertentu, seperti penunjukan beliau pada Muadz Ibn Jabal (Solikhin, 2005: 44)

Ibnu Taimiyah banyak mengungkap peranan Al Hisbah pada masa Rasulullah Saw. Sering melakukan inpeksi ke pasar untuk mengecek harga dan mekanisme pasar. Rasulullah saw juga banyak memberikan pendapat, perintah ataupun larangan demi sebuah pasar yang islami. Semua ini mengidentifikasikan secara jelas bahwa al hisbah telah ada sejak masa rasulullah saw, meskipun nama al hisbah baru dikenal pada masa kemudian (UP3EI, 2009: 342)

Sebagai lembaga pemerintah yang mengawasi pasar, lembaga hisbah memiliki beberapa peran:

a. Pengawasan terhadap kondisi keseimbangan (ekuilibrium) di berbagai sektor ekonomi islam. Dalam artian bahwa kekuatan mekanisme pasar tidak bisa di percaya sepenuhnya. Harus tetap ada akontrol agar ketika pasar dalam kondisi yang tidak stabil atau tidak seimbang bisa diintervensi untuk mengembalikan pada titik keseimbangan

b. Pengawasan dalam produksi dan alokasi (distribusi). Dalam bidang ini hisbah memberikan pengawasan dalam beberapa bentuk:

1) Pengawasan dalam sumber industri: harus mencegah produksi barang-barang yang diharamkan oleh syariat islam 
Ekonomica Sharia Volume 5 Nomor 2 Edisi Februari $2020 \mid 7$

2) Persediaan barang-barang kebutuhan masyarakat. Ia harus mengontrol dan mengawasi kketersediaan barang-baraang yang esensial untuk memenuhi kebutuhan masyarakat.

3) Kebijakan pasar terbuka. Artinya bahwa ia harus mencegah adanya praktekpasar gelap yang bisa mengakibatkan distorsi pasar. Dan juga ketentuan free entry and exit barriers harus diwujudkan

4) Peraturan dalam praktek monopoli

5) Tidak boleh ada praktek pemotongan pasar. Yaitu praktek bai najasy

6) Mencegah terhadap semua bentuk unsur yang bisa menimbulkan distorsi pasar.

c. Pengawasan terhadap harga pasar dan membuat regulasi atasnya

d. Mengawasi permasalahan kredit.Lembaga hisbah memiliki tugas untuk mengawasi kegiatan-kegiatan kredit yang bisa menimbulkan riba. Lembaga hisbah harus mengupayakan sistem kredit harus dijalankan sesuai prinsip permodalan dalam ekonomi islam.

e. Peraturan dalam hak kepemilikan. Sebagaimana dalam prinsip kepemilikan menurut ekonomi islam, bahwa hak kepemilikn individu sangat dilindungi oleh islam. Akan tetapi di sisi lain tetap ada hak sosial yang harus di patuhi oleh setiap individu,karena hak individu tidak bersifat absolut.

f. Pengawasan dalam sektor publik. Menyangkut jasa-jasa umum yang harus tetap di kontrol, seperti memastikan dilaksakannya dengan baik tugas para pejabat dibidang kesehatan, pendidikan, obat-obatan, dan lain sebagainya (Mannan, 1992: 193-194).

Jadi, Al-Hisbah melekat pada fungsi negara dalam pasar atau tidak perlu membentuk lembaga khusus. Dan al hisbah adalah semacam polisi khusus ekonomi. Bahkan lembaga ini merupakan suatu agen independen sehingga terlepas dari kepentingan kelompok tertentu atau pemerintah itu sendiri (Abdullah, 2010: 337) Oleh karena itu, seorang yang diangkat untuk memegang peran sebagai muhtasib haruslah memiliki integritas moral tinggi dan kompeten dalam masalah hukum, pasar dan urusan perindustrian. Melalui al-hisbah, negara menggunakan lembaga tersebut untuk mengontrol kondisi sosio-ekonomi secara komprehensif atas kegiatan perdagangan dan praktek-praktek ekonomi (Aravik, 2016: 41). 
8| Amrillah Pengendalian Harga Pada Program Tani Indonesia Center Provinsi Sumsel.....

\section{Pengendalian Harga Beras Dalam Perspektif Ekonomi Islam}

Dalam konsep Islam, yang paling prinsip adalah harga ditentukan oleh keseimbangan permintaan dan penawaran. Keseimbangan ini terjadi bila antara penjual dan pembeli bersikap saling merelakan. Akan tetapi apabila para pedagang sudah menaikkan harga di atas batas kewajaran, mereka itu telah berbuat zalim dan sangat membahayakan umat manusia,maka seorang penguasa (Pemerintah) harus campur tangan dalam menangani persoalan tersebut dengan cara menetapkan harga standar. Pemerintah terus berupaya melakukan langkah untuk menekan harga-harga kebutuhan pokok saat Ramadhan dan Idul Fitri (Deliarnov, 2012: 168).

Kedudukan Intervensi harga dalam ekonomi Islam sangat penting, bahwa intervensi harga merupakan unsur yang akan menetukan apakah intervensi itu dibenarkan syariah atau tidaknya suatu transaksi ekonomi. Intervensi harga ini pula yang akan membedakan apakah kegiatan itu sesui dengan syariah Islam atau tidak (Deliarnov, 2012: 169).

Jumhur Ulama sepakat bahwa harga yang adil adalah harga yang terbentuk karena interaksi kekuatan penawaran dan permintaan (mekanisme pasar). Mereka juga sepakat menolak intervensi harga oleh pemerintah, kecuali pada kondisi-kondisi tertentu intervensi pemerintah dalam bentuk pengendalian harga dibenarkan. Intervensi harga islami bertujuan untuk mengembalikan harga yang terbentuk akibat terjadinya distorsi pada harga pasar atau harga yang adil (qimah al-'adl). Dalam kajian penulis sebulnya juga telah diuraikan 4 cendekiawan besar muslim klasik yang berbicara mengenai intervensi harga, yaitu Dr. Yusuf Qardhawi, Ibnu Taimiyah, Yahya Bin Umar, Menurut mazhab Syafi'i dan Imam Malik.

Diantara mereka ada yang mempunyai pandangan yang sama dalam hal intervensi pasar yaitu Dr. Yusuf Qardhawi, Ibnu Taimiyah, Yahya Bin Umar, Menurut mazhab Syafi'i dan Imam Malik lebih menekankan pada urgensi mekanisme pasar sekalipun dalam tulisannya ditemukan anjuran untuk intervensi pemerintah tapi tidak tegas ${ }^{1}$ berikut masing-masing pemikiran mereka:

a. Dr. Yusuf Qardhawi berpandangan bahwa pasar memiliki wewenang penuh dalam penentuan harga barang, Qardhawi berpijak pada sabda Rasulullah SAWsaat

\footnotetext{
${ }^{1}$ Abdul sami’Al-Mishri, Pilar-PilarEkonomi Islam, cet 1, Pustaka Pelajar, (Yogyakarta ). 2006. hlm. 49
} 
Ekonomica Sharia Volume 5 Nomor 2 Edisi Februari $2020 \mid 9$

sahabat meminta beliau untuk menentukan harga, beliau menjawab : Allahlah yang menentukan harga, yang mencabut, yang meluaskan dan yang memberi rezeki. Saya mengharap ingin bertemu Allah sedang tidak ada seorang pun diantara kamu yang meminta saya supaya berbuat zalim baik terhadap darahmaupun harta benda" (Riwayat Ahmad, Abu Daud, Tarmizi, Ibnu Majah, ad-Darimi dan Abu Ya'la. Intevensi harga yang mengganggu kebebasan pribadi seseorang adalah sebuah kezaliman, akan tetapi apabila di pasar telah muncul hal-hal yang tidak wajar sepertimonopoli komoditas yang mempermainkan harga, maka pada saat itu penetapan harga dibolehkan agar melindungi masyarakat dari orang-orang yang menggeruk keuntungan secara semena-mena.

b. Ibnu Taimiyah, Pemikiran Ibn Tamiyah tentang masalah ini banyak dicurahkan melalui karyanya, al-Hisbah fi al-Islam dan Majmu’ Fatawa. Bagi Ibnu Taimiyah Negara memiliki otoritas sentral karena kesejahteraan manusia tidak mungkin akan tercapai tanpa adanya ikatan yang kooperatif (sangat menguntungkan) antara sesama mereka. Karena itulah pemerintah sangat diperlukan dalam mengambil kebijakan-kebijakan strategis dalam penetapan harga agar terciptanya kemakmuran bersama (Aravik, 2016: 148).

c. Yahya Bin Umar, Yahya Bin Umar sedikit berbeda dengan Dr. Yusuf Qordhawi dan ibnu taimiyah dalam memahami hadis yang diriwayatkan oleh abu daut tentang penetapan harga. Menurut yahya penetapan harga tidak boleh dilakukan dengan kata lain beliau berpandangan pemerintah tidak mempunyai hak untuk mengintervensi harga. Pemerintah yang memiliki tanggung jawab menciptakan kesejahteraan umum, hanya berhak melakukan intervensi harga ketika terjadi suatu aktivitas yang dapat membahayakan kehidupan masyarakat luas.

d. Menurut mazhab Syafi'i, penguasa tidak berhak untuk menetapkan harga, biarkan masyarakat menjual dagangan mereka sebagaimana yang mereka ing inkan. Hal ini mengingat bahwa masyarakat itu sebagai pihak yang menguasai harta mereka atas diri mereka. Dan penetapan harga merupakan belenggu terhadap mereka. Penguasa memang diperintahkan untuk melindungi maslahat umat Islam namun tidaklah pandangannya pada kemaslahatatan pembeli dengan memurahkan harga itu lebih utama dibandingkan pandangannya padakemaslahatan penjual 
| Amrillah Pengendalian Harga Pada Program Tani Indonesia Center Provinsi Sumsel.....

dengan menaikkan harga.Jika terjadi perselisihan di antara dua pihak, penjual dan pembeli, maka pihak terkait itu harus melakukan ijtihad bagi kepentingan diri mereka sendiri.

e. Sementara itu Imam Malik berpendapat sebaliknya, bahwa penguasa berhak menetapkan harga. Penetapan harga pada masyarakat itu boleh dilakukan jika dikhawatirkan pelaku pasar akan menafsirkan ketaatan kaum muslimin kepada "Mekanisme Pasar".

Dengan penafsiran yang negatif atau disalahgunakan. Semua ulama bersepakat atas intervensi harga oleh pemerintah, Namun yang benar adalah bahwa penetapan hargaitu dibolehkan. Parameternya adalah berdasarkan kepada undang-undang yang tidak memuat kezaliman terhadap pihak-pihak yang terkait, dan undang-undang tersebut diperoleh dengan memperhatikan waktu dan fluktuasi, serta situasi dan keadaan masyarakat. Apa yang disabdakan Nabi yang melarang penetapan harga itu benar. Namun, hal itu berlaku bagi suatu komunitas masyarakat yang beriman teguh dan berserah diri sepenuhnya kepada Allah SWT. Sedangkan komunitas yang bermaksud untuk memangsa sesama anggota masyarakat dan mempersulit mereka, melakukan monopoli harga maka disanala peran pemerintah untuk menjaga kestabilan harga di tengan-tengah masyarakat.

Dari pendapat ulama ulama di atas penulis menangkap maksud dari pandangan masing-masing ulama yakni hukum intervensi pemerintah terbagi menjadi dua bagian, yaitu;

1) Intervensi yang dilarang atau diharamkan, yaitu keterlibatan pemerintah dalam penetapan harga yang tidak berdasarkan kaidah-kaidah yang berlaku atau tidak memperhitungkan pasar secara tidak menyeluruh.

2) Intervensi yang diperbolehkan, yaitu keterlibatan pemerintah dalam penetapanharga ketika terjadi kondisi darurat dimana dibutuhkannya pihak ketiga dalam penetapan harga agar terciptanya keadilan antar pelaku pasar seperti Petani, produsen dan konsumen.. 
Ekonomica Sharia Volume 5 Nomor 2 Edisi Februari $2020 \mid 11$

\section{PENUTUP}

Intervensi pemerintah melalui toko Tani Indonesia Center Sumatera Selatan dalam mengupayakan efisiensi distribusi beras guna memastikan harga-harga tetap terjaga dipasaran, keterlibatan pemerintah dalam kegiatan perekonomian yang terjadi dipasar ini sangat diperlukan, apalagi ketika harga-harga bahan pokok seperti beras mengalami kenaikan harga. Dari kegiatan kegiatan yang telah dilakukan di atas Toko Tani Indonesia Center Sumatera Selatan mampu menjual beras sebanyak 267,451 Karung atau sama dengan $1.337 .255 \mathrm{~kg}$ beras pada tahun 2017 dan di tahun 2018 meningkat menjadi 297,759 Karung atau sama dengan $1.488 .795 \mathrm{~kg}$ beras pada laporan tahunan toko tani center sumatera selatan.

Tinjauan ekonomi Islam dalam memandang intervensi harga yang dilakukan pemerintah yakni ada pendapat ulama-ulama islam terhadap kebijakan dengan penafsiran yang berbeda ada negative atau juga postif. Semua ulama bersepakat atas intervensi harga oleh pemerintah, Namun yang benar adalah bahwa penetapan harga itu dibolehkan. Parameternya adalah berdasarkan kepada undang-undang yang tidak memuat kezaliman terhadap pihak-pihak yang terkait, dan undang-undang tersebut diperoleh dengan memperhatikan waktu dan fluktuasi, serta situasi dan keadaan masyarakat. Apa yang disabdakan Nabi yang melarang penetapan harga itu benar. Namun, hal itu berlaku bagi suatu komunitas masyarakat yang beriman teguh dan berserah diri sepenuhnya kepada Allah SWT. Sedangkan komunitas yang bermaksud untuk memangsa sesama anggota masyarakat dan mempersulit mereka, melakukan monopoli harga maka disanala peran pemerintah untuk menjaga kestabilan harga di tengan-tengah masyarakat. 
12 | Amrillah Pengendalian Harga Pada Program Tani Indonesia Center Provinsi Sumsel....•

\section{DAFTAR PUSTAKA}

Abdul Mannan, Teori dan Praktek Ekonomi Islam, Dhana Bhakti, Yogyakarta : 1997

Abdul sami'Al-Mishri, Pilar-PilarEkonomi Islam, cet 1, Pustaka Pelajar, (Yogyakarta ). 2006

Abdullah, Peradaban Pemikiran Ekonomi Islam. Jakarta: Pustaka Insan 2010

Airlangga, Pangan dan Terobosan-nya. Jakarta: PT. Insan Group, 2008

Anselm Strauss dan Juliet Corbin, Dasar-dasar Penelitian Kualitatif , Yogyakarta: Pustaka Pelajar Offset, 2007

Aravik, Havis, Ekonomi Islam; Teori, Konsep dan Aplikasi Serta Pandangan Pemikir Ekonomi Islam dari Abu Ubaid Sampai Al-Maududi, Malang: Empat Dua, 2016.

Aravik, Havis. "Penyelesaian Sengketa Konsumen Melalui Jalur Al-Shulhuh dan Jawatan al-Hisbah." Ekonomica Sharia 1, no. 2 (2016): 33-42.

Deliarnov. Perkembangan Pemikiran Ekonomi. Jakarta: Raja Grafindo Persada, 2012

Fathoni, Riza. 2010. "Kenaikan Harga Beras Diramal Dongkrak Inflasi Bulan Ini”, (Online)

Manan, Sistem Ekonomi Islam, Bandung: insan pers :1992

Muhammad, Metodelogi Penelitian Ekonomi Islam Kuantitatif, Jakarta: PT. Rajagrafindo Persada, 2013

Pedoman Teknis Pengembangan Usaha Pangan Masyarakat Melalui Toko Tani Indonesia Tahun 2017

Solikhin, Wilayah Hisbah Dalam Tinjauan Historis Pemerintahan Islam. Vol. 3. Purwokerto: P3M STAIN. 2005

Ummar Chapra, Islam And The Economic Challenge trj. Ikhwan Abidin. Herdhon: The Islamic Foudation. 2001

UP3EI, Ekonomi Islam. Jakarta: Rajawali Pers. 2009

Zamkhasyari, Fiqih Ekonomi Umar Bin Khatab. Jakarta: Khalifah. 2003 